\title{
Burning pain attacks and red skin in a young woman
}

\author{
Ataques de dor em queimação e eritrodermia em uma mulher jovem \\ Paulo Victor Sgobbi de Souza', Thiago Bortholin', Wladimir Bocca Vieira de Rezende Pinto', \\ Acary Souza Bulle Oliveira ${ }^{1}$
}

A 21-year-old woman presented with a five-year history of burning pain, redness, swelling and heat in her feet. The medical history disclosed palmar hyperhidrosis. Her family history was unremarkable. Examination showed erythema, heat and marked swelling in her feet, which improved after gabapentin and acetylsalicylic acid treatment (Figure). An extensive evaluation for secondary causes was unremarkable.
Erythromelalgia is characterized by recurrent attacks of intense pain, redness, warmth and swelling, localized to the distal extremities due to secondary etiologies such as myeloproliferative or rheumatologic disorders, drugs (bromocriptine; calcium channel blockers) ${ }^{1}$, or as primary erythromelalgia $^{2}$ caused by mutations in the SCN9A gene, coding sodium channel subtype Nav1.7.


Figure. Examination for erythromelalgia. Note the presence of marked erythema, heat and swelling in feet (A, B) with marked response to acetylsalicylic acid and gabapentin treatment after three weeks (C, D).

\section{References}

1. Tang Z, Chen Z, Tang B, Jiang H. Primary erythromelalgia: a review. Orphanet J Rare Dis. 2015;10:127. https://doi.org/10.1186/s13023-015-0347-1
2. McDonnell A, Schulman B, Ali Z, Dib-Hajj SD, Brock F, Cobain S et al. Inherited erythromelalgia due to mutations in SCN9A: natural history, clinical phenotype and somatosensory profile. Brain. 2016;139(4):1052-65. https://doi.org/10.1093/brain/aww007

\footnotetext{
'Universidade Federal de São Paulo, Departamento de Neurologia e Neurocirurgia, Divisão de Doenças Neuromusculares, São Paulo SP, Brasil. 